\title{
Article \\ Managing Protected Areas in a Changing World: New Insights and Opportunities
}

\author{
A. Z. M. Manzoor Rashid ${ }^{1}$ and Sharif Ahmed Mukul ${ }^{2,3,4, *}$
}

\author{
${ }^{1}$ Department of Forestry and Environmental Science, School of Agriculture and Mineral Sciences, \\ Shahjalal University of Science and Technology, Sylhet, Bangladesh \\ ${ }^{2}$ Tropical Forests and People Research Centre, University of the Sunshine Coast, Maroochydore, \\ Australia \\ ${ }^{3}$ School of Geography, Planning and Environmental Management, The University of Queensland, \\ Brisbane, Australia \\ ${ }^{4}$ Tropical Forestry Group, School of Agriculture and Food Sceices, The University of Queensland, \\ Brisbane, Australia \\ ${ }^{*}$ Corresponding author: Email address: sharif_a_mukul@yahoo.com (Sharif A. Mukul)
}

\begin{abstract}
Establishment of protected areas (PAs) is one of the key global conservation strategies that currently cover approximately $15 \%$ of the earth's land surface. Globally, PA networks are designed to curb the growing anthropogenic pressures in areas with high biological diversity. Despite the importance of PAs in conserving the vanishing biodiversity and unique habitats, many of them are in critical condition due to poor governance thus functioning below the expected level. Moreover, in many developing countries, the PA coverage is below the global standard. Recognizing their contemporary role in conservation, governments have recently agreed to expand the global PA coverage to $17 \%$ by the year 2020 (Aichi target 11). This book with eight chapters from different regions of the world provides an overview of the PAs governance, institutional mechanisms, conservation benefits, limitations and challenges associated with their respective policy discourse, integrated management, and functional attributes. Protected areas expect to to play an important role in the long in in conservation and protection of biodiversity and ecosystems particularly in countries where population pressure and habitat loss are high. Regular intervention, political commitment, and effective governance are essential for the sustainability of PAs across the world. Here, we also attempted to shed some light on future development clues for the sustainable management and monitoring of PAs worldwide.
\end{abstract}

Keywords: conservation; governance; habitat loss; livelihood; eco-tourism; carbon credits

\section{INTRODUCTION}

Protected areas (PAs) are the cornerstone of the global conservation strategy and are critical for maintaining habitat integrity and species diversity (Bode et al. 2014; Laurance et al. 2012). The term "protected area" refers to any area of land or sea managed for the persistence of biodiversity and other natural processes in situ, through constraints on incompatible land uses (Possingham et al. 2006). Protected areas and its role in conservation are not new. For quite a long it has been in use in various forms and context (Watson et al. 2014). PAs undergo massive expansion both geographically and theoretically, and they now cover approximately $15 \%$ of the earth's land surface (UNEP-WCMC 2016; Geldmann et al. 2015; Figure 1). Recognizing their role in conserving biodiversity and unique habitats, the Convention on Biological Diversity (CBD) Aichi Target 11 recently calls for a substantial expansion in terrestrial and marine protected areas by 2020 , with greater emphasis on the strategic expansion of global PA networks (Saout et al. 2013). 
Despite of the growing consensus, many PAs are not functioning as intended and the management standards of a vast majority of PAs remains ambiguous thus regarded as "paper parks" (Geldmann et al. 2015). Substantial gaps remain in the PA coverage and the establishment is still influenced by the availability of land that is easy to protect and away from strategic areas for biodiversity (Venter et al. 2014). Figure 2 below shows the PAs coverage by country across the world. It is clear that in many countries PA coverage and networks are still under the global standard to represent the unique habitats, flora, and fauna. There is also considerable debate on the extent to which PAs deliver conservation outcomes in terms of habitat loss and species conservation. Limited information regarding conservation outcomes in the context of different management inputs in PAs is quite common (Laurance 2013). A recent study by Gray et al. (2016) revealed that globally species richness is $10.6 \%$ higher and species abundance is $14.5 \%$ higher in PAs than in the surrounding landscapes. It is also true that in tropical developing region many PAs have been established after being modified by human activity and habitat conversion does not decline significantly following gazette notification of PA. In South Asia, for instance, about $25 \%$ of the land inside PAs are human-modified and within a dynamic socioecological systems (Clark et al. 2013). Establishment of PAs under such circumstances creates major conflicts with local communities posing significant management challenges (Mukul et al. 2010). This is largely due to the lack of recognition of traditional knowledge and practices, livelihood and dependency prior to the declaration of the area as PA (Chowdhury et al. 2014). In this regard, involvements of local communities in PAs management and incentives to communities dependent on PAs in many instances bring positive outcomes (Mukul et al. 2014; Rashid et al. 2013).

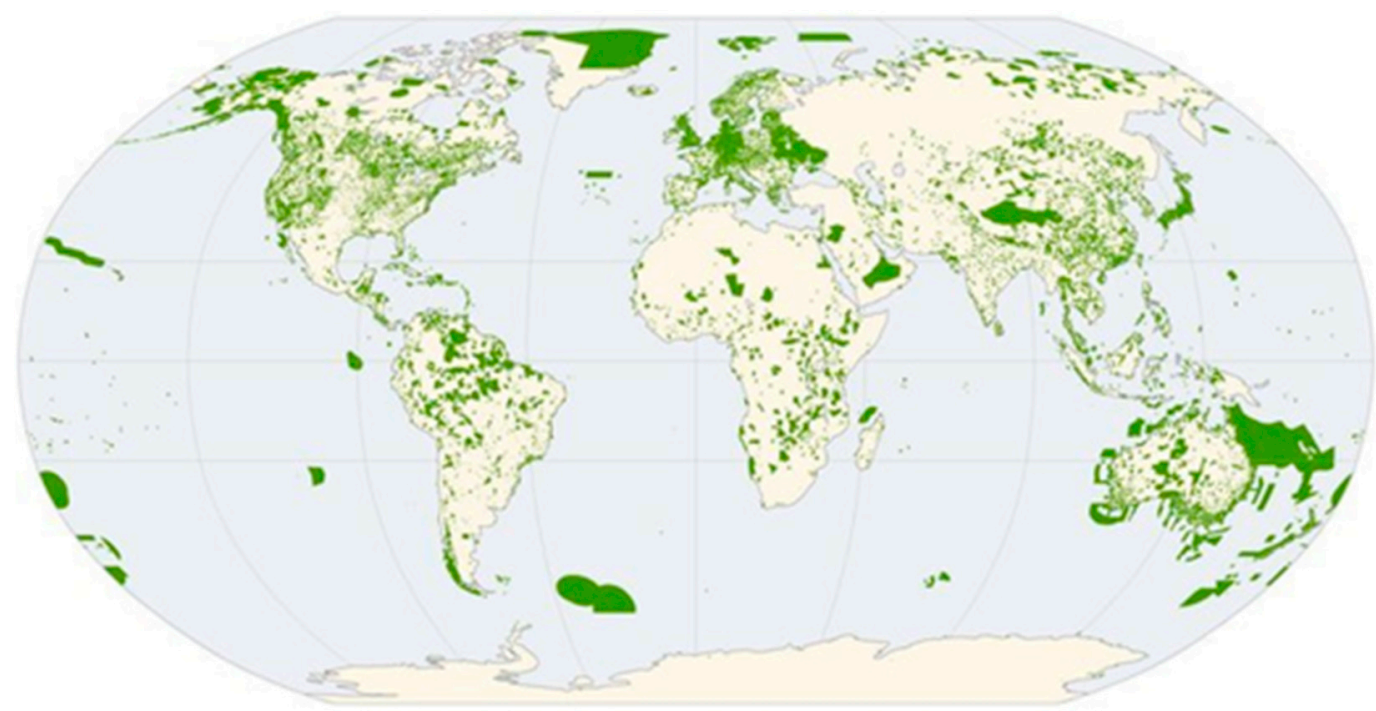

Source: UNEP-WCMC (2016).

Figure 1. Global protected are coverage (IUCN categories I-VI). 


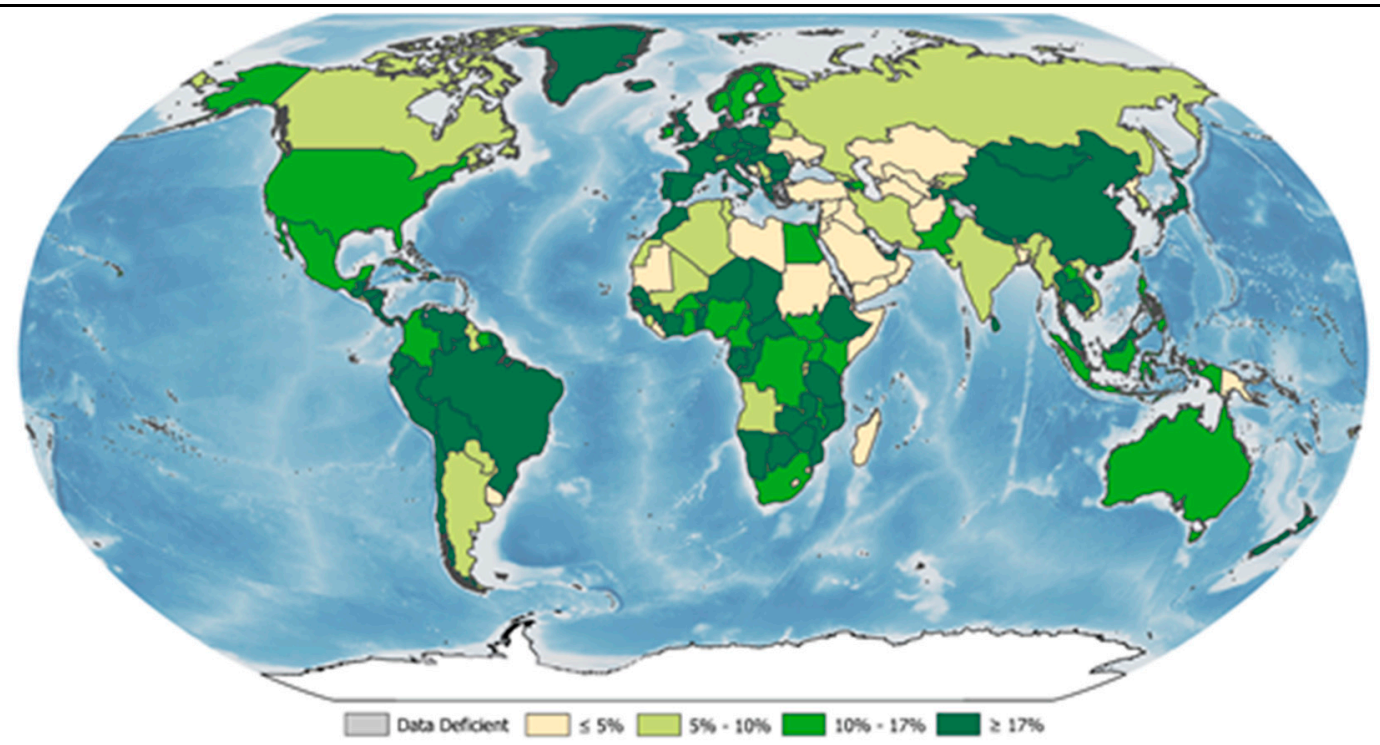

Source: UNEP-WCMC (2016).

Figure 2. Distribution of protected area systems around the world.

\section{The Benefits of Protected Area}

The primary benefit and the driving motivation of establishment of PAs is conservation of biodiversity and unique habitats (Venter et al. 2014). The role and practicality of PAs in conserving biodiversity are well recognized (Gray et al. 2016; Uddin et al. 2013). PAs also contribute significantly in curbing tropical deforestation and forest degradation (Andam et al. 2008). In fact, with deforestation advancing rapidly, many PAs in the tropics becoming the last refuges for their threatened species and critical ecosystems (Laurance et al. 2012). The recreational and aesthetic values are another two major aspect of their establishment and management. Nature-based tourism within PAs is one of the major sources of revenues from PAs worldwide (Karanth and DeFries 2011). 


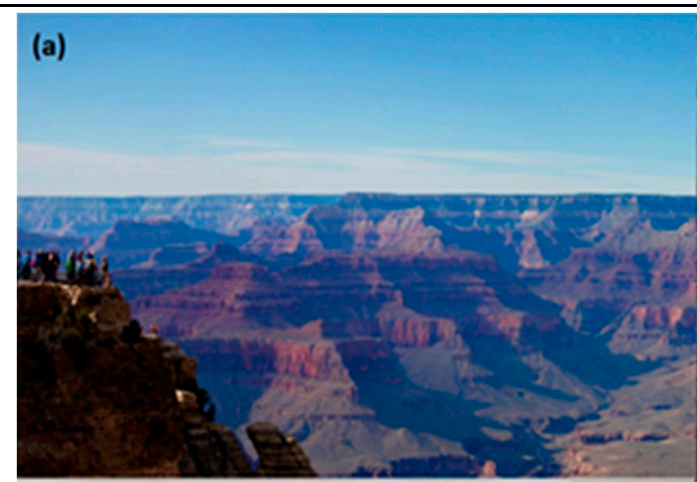

(c)
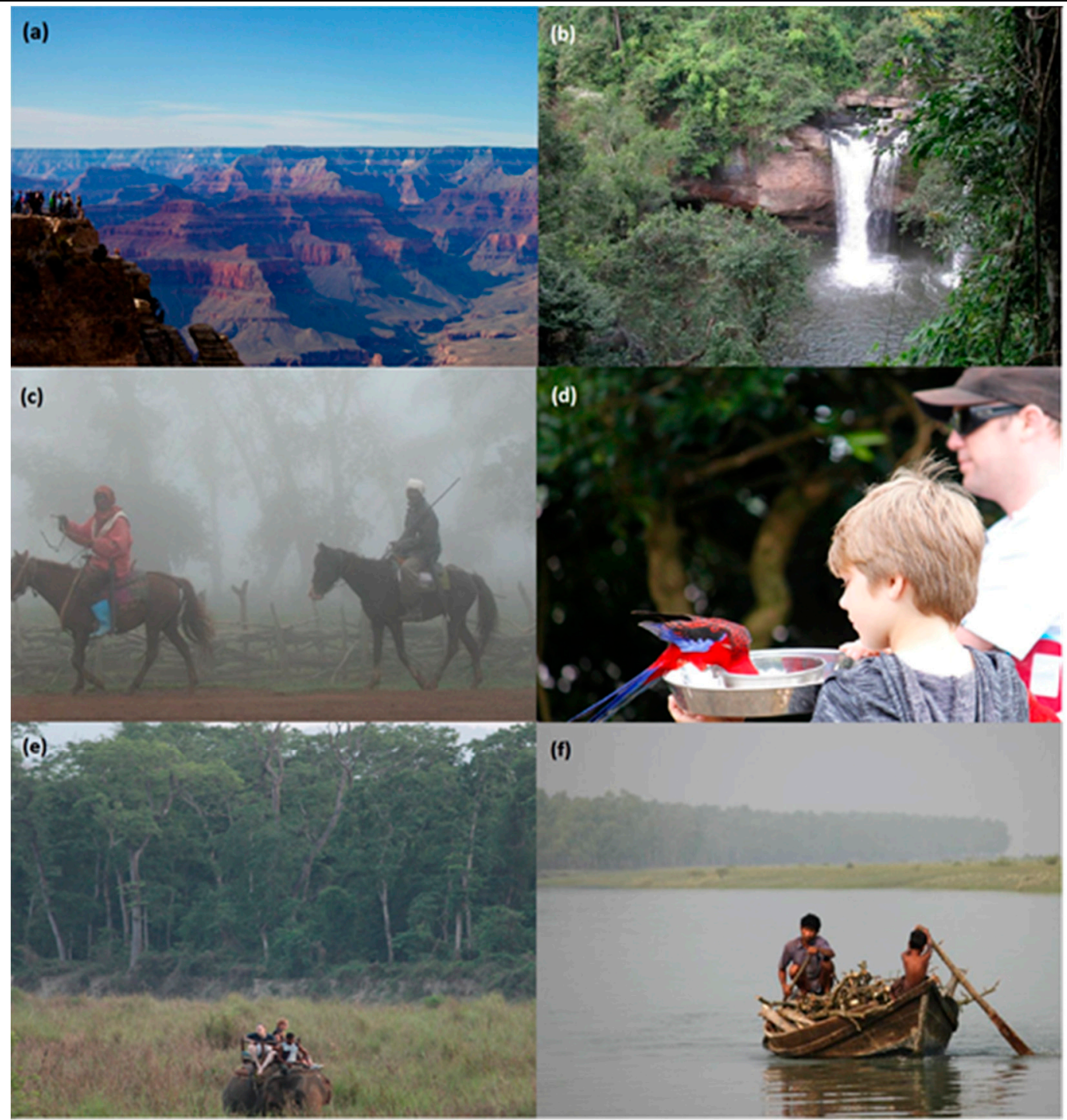

(f)

Photo credits: Sharif A. Mukul.

Figure 3. Local benefits and use of protected areas: (a) aesthetic and recreational use of Grand Canyon National Park, USA, (b) waterfall inside the Khao Yai National Park, Thailand - a major attraction to tourists, (c) monitoring of protected area by local communities in Bale Mountains National Park, Ethiopia, (d) visitors feeding birds in Lamington National Park, Australia, (e) Elephant ride by tourists inside Chitwan National Park, Nepal, (f) local extraction of firewood for domestic use in Nijhum Dwip National Park, Bangladesh.

The socio-economic benefits arising from PAs are different in developed and developing countries and mainly due to the differences in local socio-economic and cultural context (Andam et al. 2010). In both cases, the establishment of PAs brought some positive changes although the extent and magnitude of changes may not be similar (Heagney et al. 2015; Andam et al. 2010). In developing world, the benefits from PAs are limited to only a few people and/or not evenly distributed. Local peoples here usually collect timber, non-timber forest products (NTFPs), firewood, bushmeat, medicinal plants, building materials from PAs which even sometimes go against the main principle of their establishment (Mukul et al. 2010). On the other hand, in developed world, the establishment of PAs usually influence the welfare of local communities by adding values to their life and livings (Heagney et al. 2015). 


\section{OVERVIEW OF THIS BOOK}

A global zeal has already been established in regards to PA establishment and its governance for achieving the sustainable conservation and livelihood goals. This book is an attempt to revisit such development from the global point of view. Here we have accumulated eight chapters from seven different countries across the globe shedding lights on different attributes of PAs. This book believes to offer an international flavor to the readers with contemporary information on various aspects of PAs management.

Establishment of parks and protected areas provides an alternative to common pool resources that in mnay instances turns as the tragedy of the commons. The second chapter by Flemming (2016) attempts to combine some observations in regards to the governance mechanism for the accessibility of PAs currently open to all without any major restrictions. How growing populations are posing serious threats to biodiversity and natural resources of PAs is best described through using empirical examples from the global south. The chapter also tries to reveal the scenario through visitor's perception whose values for the parks are steadily eroded.

Rashid et al. (2016), in chapter 3, describes the development of a new paradigm of PA governance in Bangladesh. Good governance in natural resource management (NRM) is one of the most challenging tasks in developing countries that often inappropriately embedded in national policies and political agendas. This chapter, however, warned the practitioners and policy makers to be cautious in regards to external aid support and regulated conditioned of the donors to be taken care while introducing such approaches.

Nepal has undergone several policy reforms over the years to address multi-dimensional global conservation goals. In chapter 4, Bhattarai et al. (2016), attempted to explore a scenario in the country where conservation without participation ended up with many socio-political and other related impacts. Forced displacement of inhabitants from PA especially indigenous communities has created many social impacts including a restriction on people's customary rights to access natural resources and their livelihoods.

Mayrhuber (2016), in chapter 5, investigated the forest resource utilization in the context of complex local situations within the boundaries of the Biligiri Rangaswamy Temple (BRT) Wildlife Sanctuary in Southern India. Based on an ethnographic research approach, the study revealed that the forest areas provide an essential source of provisioning and cultural services to the forest-dwelling people in the locality.

In the next chapter, Beita and Andreu (2016) manifested the role of local level policies for ecotourism development in Latin American context. Using Costa Rica as an example chapter 6 evaluates the issue of tourism management and involvement of local people in protected areas. Local policies related to tourism management and local people's involvements in PAs management are two important approaches that need to be evaluated with a view to identify their future challenges.

In a country like Bangladesh, the concept of forest protected area (FPA) for biodiversity conservation is rather new, started only in 1980's. In chapter 7, Mukul et al. (2016) provide an overview of FPAs of Bangladesh with their role and efficacy in biodiversity conservation. The majority of the country FPAs declared only in the recent years with still limited infrastructure, manpower and policy support. The authors concluded that there are ample opportunities to make the co-management a costeffective strategy for FPA management in the country with sufficient access to local forest-dependent people in different alternative livelihood options.

Protected areas, now a days playing unique role in climate change mitigation through absorbing carbon in forest biomass and soil. Olupot et al. (2016), in chapter 8, manifested how land use and land cover (LULC) change in PAs influence carbon stock and $\mathrm{CO}_{2}$ emission in Africa using Uganda as a case study. The authors' hypothesized that any change in the LULC or shifting away from native vegetation would lead a net reduction in carbon stock in PA. The chapter suggested for the revegetation and/or restoration of degraded forests with native tree species in order to increase the carbon sequestration capacity of local forests in PAs of Uganda.

Khapugin et al. (2016) in the last chapter attempted to reveal the status of vascular plants in PAs of Mordovia located in central parts of Russia. Massive tree felling inside the PAs and anthropogenic 
pressure have deteriorated the population status of important plant species in the country. The existing PAs networks contribute to the conservation of rare and endangered plant species although a significant number of rare species has still remained outside the PA. The authors demonstrate that reorganization and strategic planning can result in an increase in rare and endangered plant species in the country's PAs network.

\section{FUTURE OUTLOOK}

With increasing global population and growing demand of land for agriculture and other use, protected areas are the last hope for earth's irreplaceable biodiversity hence should be managed as effectively as possible. Protected area networks should be designed appropriately to represent a country's unique ecosystem and biological resources that has also been revealed by Mukul et al. (2016) and Khapugin et al. (2016) in their studies. Local management in this regard must be strategically tailored to the specific biodiversity features of respective PA to secure maximum conservation outcome.

Right based approaches are the centre point of all development interventions thus local communities should be integrated into PAs governance with clearly defined rights and responsibilities. In India, Mayrhuber (2016) found that a large number of forest-dwelling people are still dependent on PAs for sustaining their livelihoods which largely determined by local regulation, tenurial arrangement, and customary rights. Exclusion of local people under such context may negatively inflcune the local livelihoods and thus threatens the ultimate aim of PAs establishment as revealed by Bhattarai et al. (2016) from Nepal. Rashid et al. (2016) also emphasized the need for people-centered approaches in PAs governance, although the authors also encouraged for local funding sources and capacity building for the long-term success of PAs system with less dependency on donor and/or program support for such kind of initiatives.

Sustainability is another crucial determinant factor for the success of PAs like many other development projects. The ever increasing population are creating serious threats to PAs in the global south similar to the north in many cases with the limited value of people for local biodiversity and natural resources (Flemming 2016). Ecotourism is a major attribute of PAs management which with suitable national policy, regulation and local intervention could also secure the sustainability of the PAs system (Beita and Andreu 2016).

New dimensions and values need to be incorporated in the management of PAs keeping climate change and other global issues into consideration. Olupot et al. (2016) found that PAs in Uganda contribute substantially to climate change mitigation. Protection of native vegetation and restoration of degraded lands with native flora have the best potential for biodiversity and carbon co-benefits. The introduction of payment for ecosystem services within PA networks including carbon credits to local communities could be a future avenue.

\section{REFERENCES}

Andam, K. S., Ferraro, P. J., Pfaff, A., Sanchez-Azofeifa, G. A., Robalino, J. A. 2008. Measuring the effectiveness of protected area networks in reducing deforestation. PNAS, 105: 16089-16094.

Andam, K. S., Ferraro, P. J., Sims, K. R. E., Healy, A., Holland, M. B. 2010. Protected areas reduced poverty in Costa Rica and Thailand. PNAS, 107: 9996-10001.

Beita, C. M., Andreu, M. N. 2016. Local level policies for tourism management in protected areas: Experiences from Costa Rica. In: Mukul, S. A., Rashid, A. Z. M. M. (eds.), Protected Areas: Policies, Management and Future Directions, pp XX-YY. Nova Science Publishers, US.

Bhattarai, S., Pant, B., Timalsina, N. 2016. Conservation without participation: detrimental effect of escaping people's participation in protected area management in Nepal. In: Mukul, S. A., Rashid, A. Z. M. M. (eds.), Protected Areas: Policies, Management and Future Directions, pp XX-YY. Nova Science Publishers, US. 
Bode, M., Tulloch, A. I. T., Mills, M., Venter, O., Ando, A. W. 2014. A conservation planning approach to mitigate the impacts of leakage from protected area networks. Conservation Biology, 29: 765774.

Chowdhury, M. S. H., Gudmundsson, C., Izumiyama, S., Koike, M., Nazia, N., Rana, M. P., Mukul, S. A., Muhammed, N., Redowan, M. 2014. Community attitudes toward forest conservation programs through collaborative protected area management in Bangladesh. Environment, Development and Sustainability, 16: 1235-1252.

Clark, N. E., Boakes, E. H., McGowan, P. J. K., Mace, G. M., Fuller, R. A. 2013. Protected areas in South Asia have not prevented habitat loss: A study using historical models of land-use change. PLoS One, 8: e65298.

Fleming, C. M. 2016. Governing the accessibility of protected areas. In: Mukul, S. A., Rashid, A. Z. M. M. (eds.), Protected Areas: Policies, Management and Future Directions, pp XX-YY. Nova Science Publishers, US.

Geldmann, J., Coad, L., Barnes, M., Craigie, I. D., Hockings, M., Knights, K., Leverington, F., Cuadros, I. C., Zamora, C., Woodley, S., Burgess, N. D. 2015. Changes in protected area management effectiveness over time: A global analysis. Biological Conservation, 191: 692-699.

Gray, C. L., Hill, S. L. L., Newbold, T., Hudson, L. N., Borger, L., Contu, S., Hoskins, A. J., Ferrier, S., Purvis, A., Scharlemann, J. P. W. 2016. Local biodiversity is higher inside than outside terrestrial protected areas worldwide. Nature Communications, 7: 12306.

Heagney, E. C., Kovac, M., Fountain, J., Conner, N. 2015. Socio-economic benefits from protected areas in southeastern Australia. Conservation Biology, 29: 1647-1657.

Karanth, K. K., DeFries, R. 2011. Nature-based tourism in Indian protected areas: New challenges for park management. Conservation Letters, 4: 137-149.

Khapugin, A. A., Chugunov, G. G., Vargot, E. V., Silaeva, T. B. 2016. Vascular plants at the protected areas network of the Republic of Mordovia: present status and prospects. In: Mukul, S. A., Rashid, A. Z. M. M. (eds.), Protected Areas: Policies, Management and Future Directions, pp XX-YY. Nova Science Publishers, US.

Laurance, W. F. 2013. Does research help to safeguard protected areas? Trends in Ecology \& Evolution, 28: 261-266.

Laurance, W. F., Useche, D. C., Rendeiro, J., Kalka, M., Bradshaw, C. J. A., Solan, S. P., Laurance, S. G., et al. 2012. Averting biodiversity collapse in tropical forest protected areas, Nature, 489: 290294.

Mayrhuber, E. A. 2016. Contested forests: insights from the Biligiri Rangaswamy Temple Wildlife Sanctuary (India) regarding the utilisation of forest resources. In: Mukul, S. A., Rashid, A. Z. M. M. (eds.), Protected Areas: Policies, Management and Future Directions, pp XX-YY. Nova Science Publishers, US.

Mukul, S. A., Herbohn, J., Rashid, A. Z. M. M., Uddin, M. B. 2014. Comparing the effectiveness of forest law enforcement and economic incentive to prevent illegal logging in Bangladesh. International Forestry Review, 16: 363-375.

Mukul, S. A., Rashid, A. Z. M. M., Khan, N. A. Forest protected area systems and biodiversity conservation in Bangladesh. In: Mukul, S. A., Rashid, A. Z. M. M. (eds.), Protected Areas: Policies, Management and Future Directions, pp XX-YY. Nova Science Publishers, US.

Mukul, S. A., Uddin, M. B., Rashid, A. Z. M. M., Fox, J. 2010. Integrating livelihoods and conservation in protected areas: understanding role and stakeholders' views on the prospects of non-timber forest products, A Bangladesh case study. International Journal of Sustainable Development \& World Ecology, 17: 180-188.

Olupot, G., Otukei, J. R., Muwanika, V. B., Esaete, J., Tabuti, J. R. S. 2016. Conversion of native vegetation in protected areas fuels $\mathrm{CO}_{2}$-equivalent losses in Uganda. In: Mukul, S. A., Rashid, A. Z. M. M. (eds.), Protected Areas: Policies, Management and Future Directions, pp XX-YY. Nova Science Publishers, US.

Possingham, H. P., Wilson, K. A. Aldeman, S. J., Vynne, C. H. 2006. Protected areas: goals, limitations, and design. In: Groom, M. J., Meffe, G. K., Carroll, C. R. (eds.), Principles of conservation biology, pp 509-551. Third edition. Sinauer Associates, Sunderland, Massachusetts, US. 
Rashid, A. Z. M. M., Craig, D., Mukul, S. A. 2016. Shifting paradigm of governance in the natural resources management of Bangladesh: centralist to pluralistic approach in the forest protected areas management. In: Mukul, S. A., Rashid, A. Z. M. M. (eds.), Protected Areas: Policies, Management and Future Directions, pp XX-YY. Nova Science Publishers, US.

Rashid, A. Z. M. M., Craig, D., Mukul, S. A., Khan, N. A. 2013. A journey towards shared governance: status and prospects of collaborative management in the protected areas of Bangladesh. Journal of Forestry Research, 24: 599-605.

Saout, S. L., Hoffmann, M., Shi, Y., Hughes, A., Bernard, C., Brooks, T. M., Bertzky, B., Butchart, S. H. M., Stuart, S. N., Badman, T., Rodrigues, A. S. L. 2013. Protected areas and effective biodiversity conservation. Science, 342: 803-805.

Uddin, M. B., Steinbauer, M. J., Jentsch, A., Mukul, S. A., Beierkuhnlein, C. 2013. Do environmental attributes, disturbances, and protection regimes determine the distribution of exotic plant species in Bangladesh forest ecosystem? Forest Ecology and Management, 303: 72-80.

UNEP-WCMC. 2016. The world database on protected areas (WDPA) [On-line]. Cambridge, UK: UNEP-WCMC. Available online at: www.protectedplanet.net.

Venter, O., Fuller, R. A., Segan, D. B., Carwardine, J., Brooks, T., Butchart, S. H. M., Marco, M. D., Iwamura, T., Joseph, L., O’Grady, D., Possingham, H. P., Rondinini, C., Smith, R. J., Venter, M., Watson, J. E. M. 2014. Targeting global protected area expansion for imperiled biodiversity. PLoS Biology, 12: e1001891.

Watson, J. E. M., Dudley, N., Segan, D. B., Hockings, M. 2014. The performance and potential of protected areas. Nature, 515: 67-73.

(C) 2016 by the authors; licensee Preprints, Basel, Switzerland. This article is an open access article distributed under the terms and conditions of the Creative Commons by Attribution (CC-BY) license (http://creativecommons.org/licenses/by/4.0/). 